\title{
Multizone Air Leakage Measurements and Interactions with Ventilation Flows in Low-Energy Homes
}

\author{
Gaëlle Guyot ${ }^{1,2^{*}}$, Jérémy Ferlay ${ }^{1}$, Evelyne Gonze ${ }^{2}$, Monika Woloszyn ${ }^{2}$, Pierre Planet ${ }^{1}$, Thibaud Bello ${ }^{1}$ \\ 1 Cerema Centre-Est \\ 46 rue St Théobald BP 128 \\ 38081 L'Isle d'Abeau Cedex, France \\ *Corresponding author: gaelle.guyot@cerema.fr \\ 2 LOCIE UMR CNRS 5271 \\ Université Savoie Mont-Blanc \\ Savoie Technolac - Bâtiment Hélios \\ Avenue du Lac Léman \\ F-73376 Le Bourget-du-Lac, France
}

\begin{abstract}
Given that airtightness is recognized as an essential issue for low-energy dwellings, today it is often included in energy performance (EP) calculations, frequently through single-zone models with uniform air leakage. Because more consideration is often given to EP than to indoor air quality issues, air leakage through internal partitions is often disregarded. Therefore, additional studies are needed to check these assumptions.

In the present study air leakage through the building envelope and through internal partitions is investigated. This paper presents the methodology used in an experimental study, conducted to measure multizone air leakages, using the guarded zone pressurization technique. We developed a detailed innovative database with 456 exterior and internal partition wall air leakage measurements, taken in 23 detached houses. For each wall, the database includes general information on the building, special requirements, the building's main characteristics, measurement protocol, type of wall, measurement input data and measurement results $\left(\mathrm{C}_{\mathrm{L}}, \mathrm{n}, \mathrm{q} \mathrm{q}_{50}\right.$ and the reliability index developed). Then an analysis of this database is provided. The analysis reveals most important relationships. For instance, internal partition wall air leakage is not related to the envelope's airtightness level; instead, the type of building structure has greater influence. Through this study, we underline the impact on building airflows of more detailed modelling of internal and external air leakage in multizone approaches, with consequences on indoor air quality (IAQ) bedrooms where people spend most of their time. As a conclusion, we propose air leakage values and dispersion input data for multizone IAQ models.
\end{abstract}

\section{KEY WORDS}

Ventilation, air leakage, measurements, single-family dwellings, indoor air quality

\section{INTRODUCTION}

Adequate air change rates are necessary to ensure good indoor air quality, including a proper humidity level in buildings. On the other hand, building energy performance (EP) requires rethinking the ventilation and the air change rates, because of their impact on thermal losses. In this context, envelope airtightness treatment becomes crucial, especially for low-energy dwellings (Erhorn et al., 2008). Indeed, envelope air leakage entails thermal losses, but also modifies theoretical voluntary airflow circuits in a building. (Boulanger et al., 2012) (Laverge and Janssens, 2013) 
confirmed that envelope airtightness promotes better ventilation performance and indoor air quality in low-energy buildings, because the theoretical airflow circuits in buildings are better controlled.

In France, the recent thermal regulation (RT2012) generalizes low-energy dwellings and requires envelope airtightness for any new dwelling. For a single-family dwelling, the airtightness requirement is $\mathrm{q}_{\mathrm{a}} \mathrm{A}=0.6 \mathrm{~m}^{3} \cdot \mathrm{h}^{-1} \cdot \mathrm{m}^{-2}$, (eq. (1)), that is around $\mathrm{n}_{50}=2.3 \mathrm{~h}^{-1}$ (eq. (2)) This EP regulation also requires an EP simulation at the design stage, based on a dynamic hourly calculation of thermal losses through the envelope, taking into account, for instance, meteorological data. The calculation checks that EP indicators are respected at the design stage with three kinds of performance requirements: 1- energy efficiency (independent of systems); 2- primary energy consumption (under approximately 50 $\mathrm{kWh} /$ year $/ \mathrm{m}^{2}$, including heating, domestic hot water, lightning, ventilation and auxiliaries) and 3- summer comfort (for buildings without air-conditioning). This is a performance-based approach.

This EP regulation does not include any new requirements on ventilation rates. The airing of dwellings comes under another 30-year-old regulation (JO, 1982), which imposes general layouts for the ventilation system and requires values for the extraction airflows in "humid" rooms, depending on the dwelling size. It uses a standardized approach.

The present paper is a part of a $\mathrm{PhD}$ thesis, which develops a performance-based approach for ventilation in lowenergy dwellings, integrating indoor air quality and health issues. This approach implies a more precise quantification of airflows in dwellings and between rooms to prevent global and/or local situations with high pollutant or humidity levels.

Since airtightness is recognized as an essential issue for low-energy dwellings, today it is often included in regulatory EP calculations, often through single-zone models with uniform air leakage (CEN, 2007), (JO, 2011). Nevertheless, when envelope air leakage is non-uniformly distributed, IAQ impacts can be strong: if a room has substantial leakage, the other rooms can also be short-circuited and become under-ventilated. Furthermore, because more consideration is often given to EP than to indoor air-quality issues, air leakage through internal partitions is often disregarded. The limits of these assumptions have already been partially studied, either through multizone airflows measurements (Reardon et al. 1987), (Gustavsen et al., 2012), or in multizone modelling studies (Roldan et al., 1987), (Richieri et al., 2013), (Laverge et al., 2013), or in combined studies (Jokisalo et al., 2008), (Offerman, 2009), (Du et al., 2012), (Hult et al., 2012). Nevertheless, additional studies are needed to collect data in order to further check these assumptions, especially in the context of low-energy houses. Therefore, in the present study air leakage through the building envelope and through 
internal partitions was investigated.

Firstly, this paper presents the methodology, with the objective of measuring multizone air leakages, using the "guarded zone" pressurization technique. These measurements were used to develop a detailed database, which includes, for each internal partition or exterior wall general information on the building, special requirements (certifications, thermal regulation), the building's main characteristics (main material, structure type, ventilation system, insulation type, number of levels, envelope airtightness), measurement protocol, type of wall, measurement input data (altitude, wind velocity, temperatures, area, volume) and measurement results $\left(\mathrm{C}_{\mathrm{L}}, \mathrm{n}, \mathrm{q}_{50}\right.$, uncertainties of derived quantities and the reliability index developed).

This paper presents the analysis of the results of this innovative database, highlighting the most important relationships.

We then propose air leakage values and dispersion input data for multizone IAQ models.

The paper concludes with on-going developments concerning a numerical multizone study using these new data.

\section{METHODOLOGY OF MULTIZONE AIR LEAKAGE MEASUREMENT CAMPAIGN ON 456 WALLS Air leakage measurement indicators}

During our campaign, we measured:

- In each house, the envelope air leakage. We used the French indicator $\mathrm{q}_{\mathrm{a} 4}\left[\mathrm{~m}^{3} \cdot \mathrm{h}^{-1} \cdot \mathrm{m}^{-2}\right]$, eq. (1), which uses the envelope area excluding the lowest floor, converted into air change per hour at $50 \mathrm{~Pa} \mathrm{n}_{50}\left[\mathrm{~h}^{-1}\right]$, eq. (2).

- In each room, the exterior wall air leakage, to obtain data on the envelope air leakage distribution on each exterior wall of the house. We used the air change rate $\mathrm{q}_{50}\left[\mathrm{~m}^{3} \cdot \mathrm{h}^{-1} \cdot \mathrm{m}^{-2}\right]$, eq. (3) and the equivalent air leakage area $\mathrm{ELA}_{4}\left[\mathrm{~cm}^{2}\right]$, eq. (4).

- In each room, the internal partition wall air leakage, to obtain data on quantification and distribution of air circulating from one room to another. We used the air change rate $\mathrm{q}_{50}\left[\mathrm{~m}^{3} \cdot \mathrm{h}^{-1} \cdot \mathrm{m}^{-2}\right]$, eq. (3), and the equivalent air leakage area $\mathrm{ELA}_{4}\left[\mathrm{~cm}^{2}\right]$, eq. (4). 


$$
\begin{gathered}
q_{a 4}=\frac{C_{L^{*}(4)^{n}}}{A_{\text {env }}} \\
n_{50}=\frac{C_{L} *(50)^{n}}{V} \\
q_{50}=\frac{C_{L} *(50)^{n}}{A} \\
E L A_{4}=\frac{C_{L}}{C_{D}} * \sqrt{\frac{\rho_{0}}{2}} * \Delta P_{r}^{n-0.5} * \frac{1}{3.6}
\end{gathered}
$$

where $C_{L}$ is the air leakage coefficient $\left[\mathrm{m}^{3} \cdot \mathrm{h}^{-1} \cdot \mathrm{Pa}^{-\mathrm{n}}\right] ; 4$ is a 4-Pa reference pressure difference across the building envelope; $\mathrm{n}$ is the airflow exponent [-]; $\mathrm{A}_{\mathrm{env}}$ is the envelope area excluding the lowest floors $\left[\mathrm{m}^{2}\right] ; 50$ is a 50 -Pa reference pressure difference across the building envelope or across the measured wall; $\mathrm{V}$ is the building's heated volume $\left[\mathrm{m}^{3}\right]$; $\mathrm{A}$ is the area of the measured wall; $\rho_{0}$ is the standard air density $\left[\mathrm{kg} \cdot \mathrm{m}^{-3}\right] ; \mathrm{C}_{\mathrm{D}}$ is the discharge coefficient $[0,0] ; \Delta \mathrm{P}_{\mathrm{r}}$ is the reference pressure difference [4 Pa].

These indicators are all derived from the power-law function, eq. (5), linking the airflow through the envelope leaks $\left[\mathrm{m}^{3} \cdot \mathrm{h}^{-1}\right]$ to the pressure difference across the building envelope $\Delta P[\mathrm{~Pa}]$ :

$$
Q=C_{L} * \Delta P^{n}
$$

\section{Description of the 23-house sample}

Table 1 gives a description of the sample: the year the building was commissioned, whether the structure was a heavy (concrete, bricks or concrete blocks) or a light construction (wood), certification, the number of levels, the ventilation system, the floor area and the envelope airtightness value. Five types of ventilation system exist: no ventilation (4\%), balanced ventilation (called "Balanced", 39\%), humidity-controlled balanced ventilation (called "Bal.DCV", 4\%), exhaust ventilation (called "Exhaust", 13\%) and humidity-controlled exhaust ventilation (called "DCV Ex", 39\%) (Figure 1).

The certification provides information on envelope airtightness. In the 2005 French low-energy certification (BBC) and in the recent French EP regulation (RT2012), envelope airtightness must be under $\mathrm{q}_{\mathrm{a} 4}=0.6 \mathrm{~m}^{3} \cdot \mathrm{h}^{-1} \cdot \mathrm{m}^{-2}$. In the Passivhaus certification, it must be under $\mathrm{n}_{50}=0.6 \mathrm{~h}^{-1}$. Sixty per cent of the houses in the sample fulfil the low-energy and envelope airtightness certification requirements.

Wood material (39\%), wood structures (35\%) and balanced ventilation systems (43\%) were more numerous in this sample than in the new building stock (Figure 1). They account for only a small fraction of the new dwelling stock in 
France.

Table 1. Characteristics of the 23 houses measured

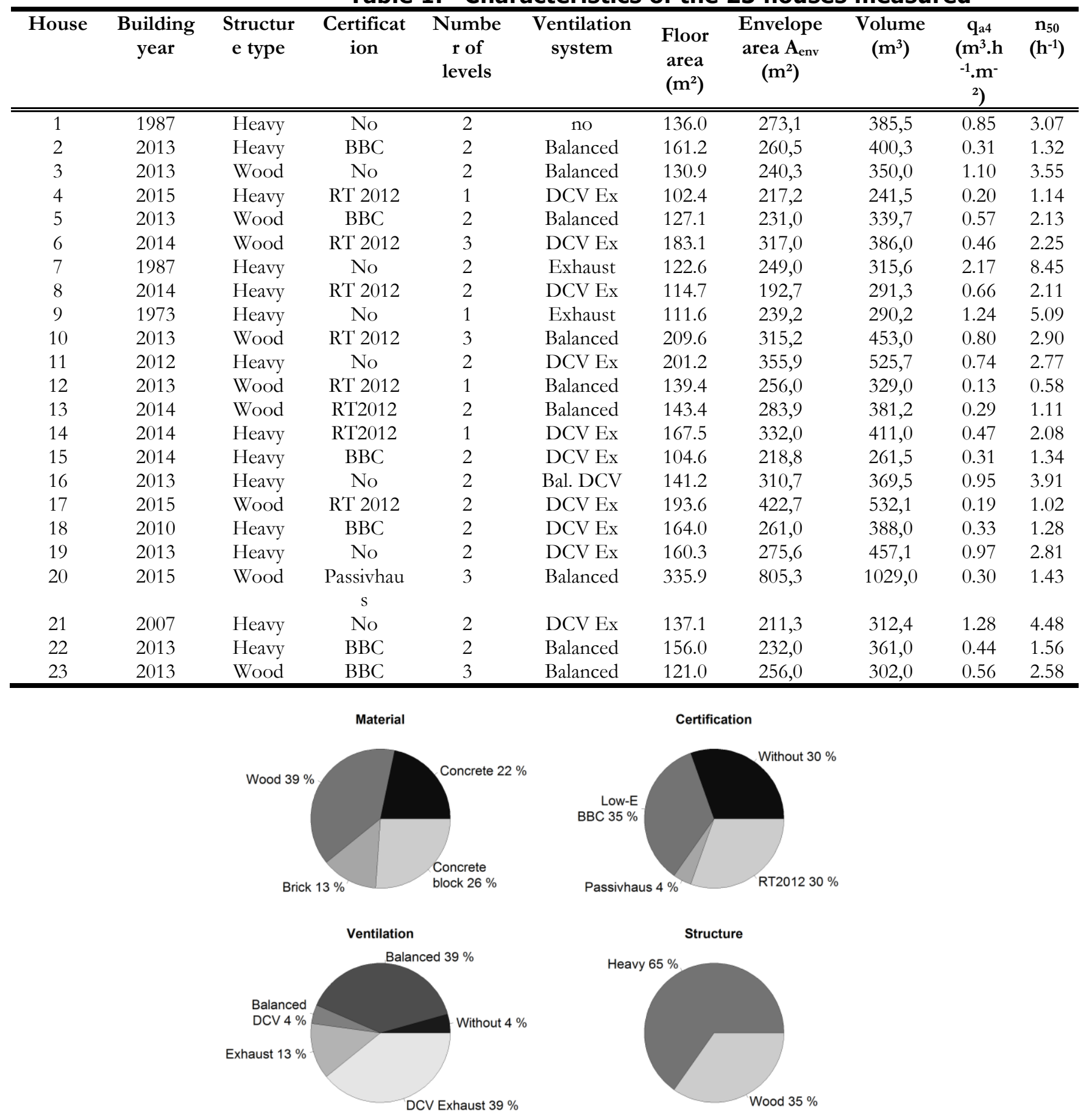


Figure 1 Overview of the 23-house sample.

\section{Measurement protocol}

Multizone air leakage measurement methods in the literature. Interest in multizone air leakage measurements began in the 1980s with studies measuring air leakage with tracer gas (Roldan et al., 1987) or with depressurization techniques such as the balanced fan pressurization technique (Shaw, 1980), (Reardon et al., 1987). (Fürbringer et al., 1988) further developed the balanced fan pressurization technique with a special device and called this method the guarded zone method. This method made it possible to measure the air leakage of a wall, using two depressurization devices. The first one is used to depressurize the building envelope. The second one is used on the guarded zone in order to maintain a zero-pressure between the guarded zone and the rest of the building, and to measure airflow through the studied wall. During the first step of the method, the exterior wall air leakage of the guarded zone is measured. Then the measurement can be repeated after having opened adjacent zones, step-by-step, outdoors to balance exterior pressure. Consequently, guarded zone internal partition wall air leakage can be obtained by subtraction at each step (Figure 2). In the literature, air leakage multizone measurements have rarely been conducted on internal partition walls in houses (Reardon et al. 1987), but instead on walls separating dwellings in multi-family buildings (Fürbringer et al., 1988), (Herrlin and Modera, 1988), (Hult et al., 2012), or between houses and their garages (Offerman, 2009), (Emmerich et al., 2003), (Hult et al., 2012).
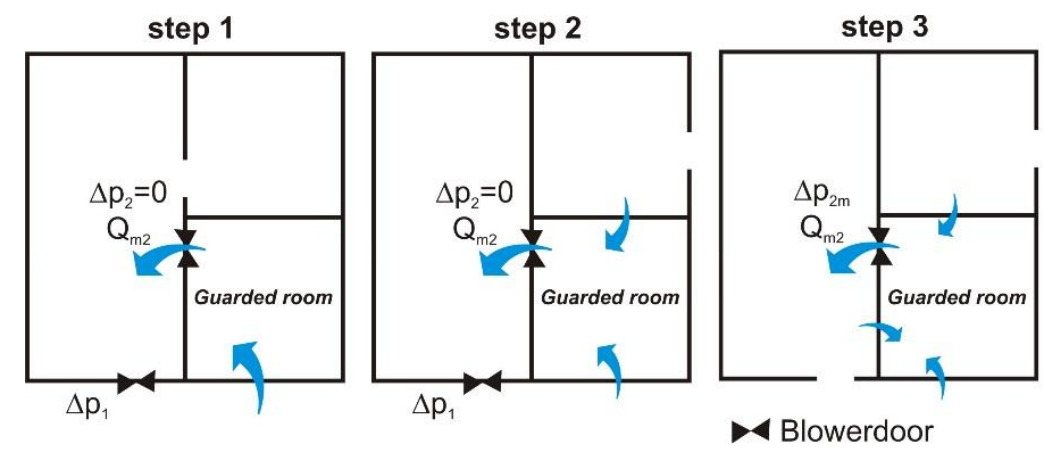

Figure 2 Illustration of the guarded zone method. Step 1: Only the external leakage is measured through device no. 2. Step 2: Additional air leakage from the first adjacent room is measured. Step 3: Additional air leakage from the second adjacent room is measured. 
Air leakage accuracy in the literature. Because the airleakage is not directly measured, but extrapolated from measurable parameters, airleakage accuracy is not only a measurement accuracy problem, but also a modelisation accuracy problem (Sherman and Palmiter, 1995). Indeed, airflows are not measurable at low pressures (under $4 \mathrm{~Pa}$ ) than the houses normally experience. This paradigm is well summarized by (Walker et al., 2013): "Unfortunately, the more precise the blower door measurements are, the larger the extrapolation error becomes, making the most precise measurements the least accurate ones". (Sherman and Palmiter, 1995) suggest that airleakage error must be calculated as the square root of the sum of the squared errors from measurement and modelisation.

Estimating a multi-points airleakage measurement accuracy through the measurement uncertainty is well documented. Sources of errors during an envelope air leakage measurement have several origins, including precision and bias of the measurement devices, the impact of the user, the impact of the meteorological data and derived quantity uncertainties. The ISO guide (ISO/IEC, 2008) proposes a general method to estimate the expanded uncertainty of a measurement. (Sherman and Palmiter, 1995) proposed to consider the measurement error as the square root of the sum of the squared errors from precision, considered as the regression analysis error, and the bias. (Delmotte, 2013) and (Alfano et al., 2012) pointed out that the EN ISO 9972 proposes only a method to estimate the uncertainty on the derived quantity through a regression analysis, but that concerning the overall uncertainty, this standard just includes a general sentence "the overall uncertainty can be estimated using the error propagation calculation". These both authors proposed two applications of the method described in the ISO guide (ISO/IEC, 2008) to the airleakage measurement proposed in EN ISO 9972. They describe formulations respectively for the combined standard uncertainty and the relative expanded uncertainty of the airleakage rate at $50 \mathrm{~Pa}, \mathrm{n}_{50}$. According to (Alfano et al., 2012), the relative expanded uncertainty on $\mathrm{n}_{50}$ ranges from 10 to $15 \%$, and can increase up to $20-40 \%$ when measurements are no repeatable or when measurement devices are not calibrated.

According to ISO guide (ISO/IEC, 2008), reproducibility (different operators, different measurement devices) and repeatability (same operator, same equipment) are indeed two influence quantities that may affect measurement uncertainty and that can be used in the definition of the uncertainty budget. (Bracke et al., 2016) recently studied 
repeatability of the pressurization test on two passive houses and reported average standard deviations less than $2.7 \%$ within the same day, with an average maximum variation of $7.7 \%$. These results are quite consistent with those of previous studies on airleakage measurement reproducibility and/or repeatability reviewed in this paper (Persily, 1982), Kim and Shaw, 1986), (Murphy et al., 1991), (Delmotte and Laverge, 2011).

Finally, it seems also important to mention in this field, that (Delmotte, 2013) and (Sherman and Palmiter, 1995) underlined that the application of a weighted method of least-squares is generally more appropriate, than the usually used unweighted method, in the framework of building airleakage measurement. Indeed, such a method allows taking into account the fact that errors change substantially over the range of measurement.

Uncertainties related to the air leakage multizone measurement techniques are also well documented. With tracer gas techniques, uncertainties were estimated around 25\% (Roldan et al., 1987). Using an especially developed device, uncertainties related to balanced fan pressurization techniques were estimated between 10\% (Fürbringer et al., 1988) and 15\% (Shaw, 1980). It could be reduced to 10\%, taking into account errors due to a wind velocity lower than 5 m.s1, if the base pressure in the guarded zone is kept at $50 \mathrm{~Pa}$ instead of $0 \mathrm{~Pa}$ (Herrlin and Modera, 1988). These authors showed that the wind impact is lower than the quality of the measurement protocol by itself, which might cause uncertainties around 40\% when measurement is imperfect. In a more recent study (Hult et al., 2012) (Hult and Sherman, 2014), the authors were looking for the simplest measurement method (with one depressurization device) that could give the most robust and precise results concerning the air leakage of a wall located between a house and an attached garage. Using a single depressurization device, they developed a method with only $20 \%$ uncertainty. This method was based on measurement within six pressure difference ranges on the house envelope, when the garage is open to outdoor pressure and then on the garage, once the house had been closed.

Literature concerning airleakage modelisation accuracy is more limited. Nevertheless, from analysis of the powerlaw function, eq. (5), and from regression analysis methods (EN ISO 9972), we can identify that modelisation errors come in many forms. Firstly, we assume that the pressure across the envelope is uniform, which is very theoretical because of the wind pressures, and not physically resolved by the correction proposed in the EN ISO9972 with the baseline pressures measurements. Recent studies (Walker et al., 2014), (Carrié and Leprince, 2014) have shown that wind velocity, could have a substantial impact on envelope airtightness accuracy. On a simple model, with steady-state 
wind and one measurement point, (Carrié and Leprince, 2014) showed that, for wind speeds up to $10 \mathrm{~m} \cdot \mathrm{s}^{-1}$, modelisation errors could account for $12 \%$ on the airflow rate at a pressure point of $50 \mathrm{~Pa}$ and for $60 \%$ at $10 \mathrm{~Pa}$. Secondly, we neglect the deviation of the flow exponent over the range of pressures (Sherman, 1992). (Sherman and Palmiter, 1995) listed other assumptions, which could add modelisation errors: the equality between the airflow through the envelope and the flow through the ventilator, the consistent character of the air density passing through the fan during the test, the extrapolation of the airflow using a power-law formulation beyond the measurement limits (for indicators at 4 Pa: ELA 4 or $\mathrm{q}_{\mathrm{a}}$ ). These authors conclude that well characterized data are missing in order to determinate the size of the modelisation errors.

When using the guarded zone method, leakage airflows are not measured directly but are calculated indirectly, by a subtraction method developed in the following paragraphs. As explained by (Herrlin and Modera, 1988), we also add new modelisation errors to all classical envelope air leakage modelisation errors stemming from this method. Notably, it is assumed that the measured zero pressure between the guarded zone and adjacent zones is uniform.

Description of the selected protocol. In this study, we used the guarded zone method with two depressurization devices (Fürbringer et al., 1988), Figure 2. The guarded zone here discussed is always made up of one opening, the one where the blower door test is installed. In the first campaign conducted in 2014, two devices accommodating airflow rates ranging from 19 to $7200 \mathrm{~m}^{3} \cdot \mathrm{h}^{-1}$ were used. With these devices, we were not able to measure some low airflows through some very airtight walls. In the second campaign in 2015, we used two types of device: device 1 accommodated an airflow rate ranging from 19 to $7200 \mathrm{~m}^{3} \cdot \mathrm{h}^{-1}$ and device 2 an airflow rate ranging from $0.61 \mathrm{~m}^{3} \cdot \mathrm{h}^{-1}$ to $1393 \mathrm{~m}^{3} \cdot \mathrm{h}^{-1}$. Device 2 was used on the guarded zone, where low airflows could be measured. All these measurement devices comply with French standard annex (AFNOR, 2014). So that maximum permissible error of differential pressure measurement devices is less than $1 \mathrm{~Pa}$ in the range $[-100 \mathrm{~Pa},+100 \mathrm{~Pa}]$, that maximum permissible error of airflow measurement devices is less than the maximum between $2 \mathrm{~m}^{3} / \mathrm{h}$ and $7 \%$ times the airflow in the used range, and that corresponding certificates are less than a year old. On each room, we used the guarded zone method to determine each wall air leakage, except for the toilet where only an envelope air leakage measurement was taken. At each step, we took measurements during 30 seconds with 100 points at eight pressure ranges $[\Delta \mathrm{P}=-10 ;-20 ;-30 ;-40 ;-50 ;-65 ;-80 ;-95 \mathrm{~Pa}]$ measured with device 1. The highest pressure is close from $100 \mathrm{~Pa}$, since the EN ISO 9972 recommends to take readings up to $100 \mathrm{~Pa}$ 
for a best measurement accuracy of calculated results, as demonstrated in the literature by (Delmotte and Laverge, 2011) and (Walker et al., 2013). Once steady state had been obtained with the two depressurization devices, we simultaneously plotted airflow at device 2 and pressure difference at device 1.

At each step, we evaluated wind velocity (Beaufort scale), temperatures (indoors, in the guarded zone, outdoors) and zero pressure differences to perform corrections according to EN ISO 9972. During tests using this method, air entering the guarded zone was mixed air between outdoor air and air in the adjacent zones, which was not exactly at the outside temperature even if windows were open. Nevertheless, we considered the outdoor temperature to perform the corrections on airflows. If large gaps were observed, we used an estimated value between outdoor and indoor temperatures. Then the time duration for one measurement (around $20 \mathrm{~min}$ ) was low enough to consider constant temperatures during the test.

For each house, an envelope air leakage test was also performed, according to the EN ISO 9972 and GA P50-784 standards.

Meteorological conditions. The measurements were not taken during the winter to avoid high temperature differences between indoor and outdoor environments and high wind velocities. The first campaign was undertaken during spring 2014 and the second one during summer and fall 2015. For some houses (no. 2, 3, 5, 21, 22, 23), a meteorological station was available and allowed us to check that wind velocity was low enough to not decrease measure accuracy. However, in five houses wind velocity was quite high (6 on the Beaufort scale) in 41 cases ( $9 \%$ of the sample). We decided to keep these measurements and to analyse them using a reliability index (developed below).

Measurement campaign. Table 2 gives an overview of the measurement campaign conditions for the 23 houses and the 456 air leakage measurements on exterior and internal partition walls. The wind exposure is characterized by 0 if the tested house is located in an urban area or strongly sheltered by obstacles in a rural area, by 1 is the tested house is located in a rural area but with some obstacles around, by 2 if the tested house is located in a rural area without any obstacle to the wind.

Table 2. Synthesis of campaign measurement conditions 


\begin{tabular}{|c|c|c|c|c|c|c|}
\hline House & $\begin{array}{l}\text { Measurement } \\
\text { period }\end{array}$ & $\begin{array}{c}\text { Air leakage } \\
\text { measurement } \\
\text { devices }\end{array}$ & $\begin{array}{c}\text { Maximum } \\
\text { wind } \\
\text { (Beaufort } \\
\text { scale) } \\
\end{array}$ & $\begin{array}{c}\text { Outdoor } \\
\text { median } \\
\text { temperature } \\
\left({ }^{\circ} \mathrm{C}\right) \\
\end{array}$ & $\begin{array}{c}\text { Wind } \\
\text { exposure (-) }\end{array}$ & $\begin{array}{c}\text { Number of } \\
\text { walls for air } \\
\text { leakage } \\
\text { measurements }\end{array}$ \\
\hline 1 & July 2015 & type $2 *$ & 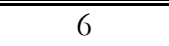 & 25 & 0 & 25 \\
\hline 2 & July 2015 & type $2 *$ & 0 & 22 & 1 & 25 \\
\hline 3 & July 2015 & type $2 *$ & 0 & 27 & 1 & 22 \\
\hline 4 & July 2015 & type $2^{*}$ & 0 & 17 & 1 & 19 \\
\hline 5 & July 2015 & type $2 *$ & 3 & 28 & 1 & 16 \\
\hline 6 & August 2015 & type $2 *$ & 0 & 25 & 1 & 28 \\
\hline 7 & August 2015 & type $2^{*}$ & 0 & 19 & 0 & 25 \\
\hline 8 & August 2015 & type $2 *$ & 4 & 19 & 2 & 20 \\
\hline 9 & August 2015 & type $2^{*}$ & 0 & 19 & 1 & 13 \\
\hline 10 & August 2015 & type $2^{*}$ & 6 & 19 & 0 & 18 \\
\hline 11 & September 2015 & type $2^{*}$ & 6 & 22 & 2 & 18 \\
\hline 12 & September 2015 & type $2 *$ & 1 & 20 & 2 & 14 \\
\hline 13 & September 2015 & type $2^{*}$ & 1 & 16 & 0 & 21 \\
\hline 14 & September 2015 & type $2 *$ & 6 & 19 & 2 & 13 \\
\hline 15 & September 2015 & type $2 *$ & 6 & 19 & 2 & 20 \\
\hline 16 & October 2015 & type $2 *$ & 1 & 13 & 0 & 20 \\
\hline 17 & October 2015 & type $2 *$ & 1 & 15 & 2 & 19 \\
\hline 18 & October 2015 & type $2 *$ & 1 & 13 & 2 & 24 \\
\hline 19 & October 2015 & type $2 *$ & 1 & 12 & 1 & 18 \\
\hline 20 & October 2015 & type $2 *$ & 1 & 5 & 2 & 15 \\
\hline 21 & April 2014 & type $1 *$ & 1 & 21 & 1 & 19 \\
\hline 22 & March 2014 & type $1 *$ & 1 & 24 & 1 & 29 \\
\hline 23 & May 2014 & type $1 *$ & 1 & 24 & 1 & 15 \\
\hline
\end{tabular}

* Type 1 = two devices, 1 with airflows ranging from 19 to $7200 \mathrm{~m}^{3} \cdot \mathrm{h}^{-1}$, type $2=$ device 1 and device 2 with airflow ranging from 0.61 to $1393 \mathrm{~m}^{3} \cdot \mathrm{h}^{-1}$.

\section{Method for measurement analysis}

Measurement data analysis. The calculation of wall air leakage from the set of measurements is described below with greater precision. For each room, at step 1 (Figure 2), $\left\{\Delta \mathrm{p}_{\mathrm{m}, 1, \mathrm{k}} ; \mathrm{Q}_{\mathrm{r}, 1, \mathrm{k}}\right\}$ were measured and read, and then corrected according to EN ISO 9972 to obtain $\left\{\Delta \mathrm{p}_{1, \mathrm{k}} ; \mathrm{Q}_{1, \mathrm{k}}\right\}$ sets, eqs. (6-7). Then the air leakage characteristics for the exterior wall $\left\{\mathrm{C}_{\mathrm{L} 1} ; \mathrm{n}_{1}\right\}$ were calculated, eqs. (8-13). At step 2, we performed the same calculations, then starting from $\left\{\mathrm{C}_{\mathrm{L} 2} ; \mathrm{n}_{2}\right\}$, a new set of data $\left\{\Delta \mathrm{p}_{1, \mathrm{k}} ; \mathrm{Q}_{12, \mathrm{k}}\right\}$ was calculated by a subtraction, eq. (14). This set was then used to calculate air leakage characteristics for this internal partition wall $\left\{\mathrm{C}_{\mathrm{L} 12} ; \mathrm{n}_{12}\right\}$, eq. (12\&15). Finally, the airleakage rate $\mathrm{Q}_{50}$ of the wall was calculated using these characteristics, eq. (16).

$$
y_{j, k}=\ln \left(\Delta p_{j, k}\right) ; \Delta p_{j, k}=\Delta p_{m, j, k}-\frac{\Delta p_{0, j, 1}+\Delta p_{0, j, 2}}{2}
$$

where $\Delta p_{m, j, k}$ is the measured difference pressure at step $\mathrm{j}$ of the guarded zone method and at point $\mathrm{k}$ of the depressurization method composed of $\mathrm{N}$ points; $\Delta p_{0, j, 1}$ and $\Delta p_{0, j, 2}$ are respectively the zero-flow pressure differences measured at the beginning and at the end of the test. 


$$
x_{j, k}=\ln \left(Q_{j, k}\right) ; Q_{j, k}=Q_{r, j, k} *\left(\frac{\rho_{j, \text { int }}}{\rho_{j, \text { out }}}\right) * \sqrt{\frac{\rho_{0}}{\rho_{j, \text { int }}}}
$$

where $Q_{r, j, k}$ is the read airflow on measurement device at step $\mathrm{j}$ of the guarded zone method and at point k of the depressurization method composed of $\mathrm{N}$ points; $\rho_{j, \text { int }}$ and $\rho_{j, \text { out }}$ are respectively the internal and external air densities [kg.m $\left.{ }^{-3}\right]$ deduced from temperatures measurements at step $\mathrm{j}$ of the guarded zone method.

$$
\begin{aligned}
& \bar{y}_{j}=\frac{1}{N} \sum_{k=1}^{N} y_{j, k} \\
& \bar{x}_{j}=\frac{1}{N} \sum_{k=1}^{N} x_{j, k} \\
& S_{x y, j}=\frac{1}{N-1} \sum_{k=1}^{N}\left(x_{j, k}-\bar{x}_{j}\right)\left(y_{j, k}-\bar{y}_{j}\right) \\
& S_{x^{2}, j}=\frac{1}{N-1} \sum_{k=1}^{N}\left(x_{j, k}-\bar{x}_{j}\right)^{2} \\
& n_{j}=\frac{s_{x y, j}}{S_{x^{2}, j}} \\
& C_{L, j}=\left(\frac{\rho_{j, i n t}}{\rho_{0}}\right)^{1-n_{j}} * e^{\bar{y}_{j}-n_{j} * \bar{x}_{j}} \\
& Q_{12, k}=C_{L 2}\left(\Delta p_{1, k}\right)^{n 2}{ }_{-} C_{L 1}\left(\Delta p_{1, k}\right)^{n 1} \\
& C_{L 12}=\left(\frac{\rho_{2, i n t}}{\rho_{0}}\right)^{1-n_{12}} * e^{\bar{y}_{1}-n_{12} * \bar{x}_{12}} \\
& Q_{50,12}=C_{L, 12}(50)^{n_{12}}
\end{aligned}
$$

Airleakage accuracy and construction of a reliability index. In this study, low airflows were encountered, with direct and indirect measurements including a subtraction, eq. (14), sometimes with high wind velocities. We were also exposed to measurement and modelisation errors, on which characterization data are missing (Sherman and Palmiter, 1995). We decided to keep all the data and used a reliability index, $I_{R}$, to describe the confidence we have in every calculated wall air leakage. This index can be calculated starting from three-error estimation parameters $\mathrm{e}_{\mathrm{i}}$, eq. (17). $\mathrm{I}_{\mathrm{R}}$ is $100 \%$ for high reliability measurements. 


$$
I_{R}(\%)=\frac{1}{3} \sum_{1}^{3} e_{i}
$$

- $\mathbf{e}_{1}$ is derived from the $\mathrm{Q}_{50}$ measurement precision error estimation, $\mathrm{E}_{1}$, resulting in eqs. (7-9). We used the Annex C of EN ISO 9972, to calculate the standard uncertainty associated with a $Q_{50}$ airleakage measurement, analysed trough a linear regression, which we note $\varepsilon 1$. This calculation is obviously not relevant if the measurement points do not describe a line Since airflow was measured indirectly, using a subtraction, and modelisation associated errors are not directly calculable, we consider as acceptable for $\mathrm{r}^{2}$ a range of [0.9;1]. Eq. (23) fulfills $\mathrm{E}_{1}=\varepsilon_{1}$ when $\mathrm{r}^{2}=0.98 ; \mathrm{E}_{1}=2 \varepsilon_{1}$ when $\mathrm{r}^{2}=0.9$, and proposes a linear extrapolation between these both values, determining the parameters $\mathrm{a}=-12.5$ and $\mathrm{b}=13.25$.

$$
\begin{array}{r}
\varepsilon_{1}=U\left(Q_{50,12}\right)=\frac{1}{2}\left(e^{I_{y, 12}(\ln (50))}-e^{-I_{y, 12}(\ln (50))}\right) \\
I_{y, 12}=S_{y, 12}(\ln (50)) * t_{95, N-2}
\end{array}
$$

where $t_{95, N-2}$ is the two-sided confidence limits for a student's t-distribution at a level of confidence of $95 \%$ and with $\mathrm{N}$ measurements.

$$
\begin{gathered}
S_{y, 12}(\ln (50))=S_{n, 12}\left(\frac{N-1}{N} S_{x, 12}^{2}+\left(\ln (50)-\bar{x}_{12}\right)^{2}\right)^{1 / 2} \\
S_{n, 12}=\frac{1}{S_{x, 12}}\left(\frac{S_{y, 12}^{2}-n_{12} * S_{x y, 12}}{N-2}\right)^{1 / 2} \\
E_{1}=\varepsilon_{1} \text { if } r^{2}>0.98 \\
E_{1}=\left(\mathrm{a} r^{2}+\mathrm{b}\right) \varepsilon_{1} \text { if } r^{2} \epsilon[0.98 ; 0.9] \\
E_{1}=\max \left(1 ; 2 \varepsilon_{1}\right) \text { if } r^{2}<0.9
\end{gathered}
$$

- $\mathbf{e}_{2}$ can be considered as the confidence we have in the calculated $n$ exponent. The $n$-value must be between 0.5 and 1 corresponding to fully turbulent developed and laminar flows (Walker et al., 1998), in this range the value for $\mathrm{e}_{2}$ is $100 \%$ (Table 3). (Sherman, 1992) demonstrated that the $\mathrm{n}$ exponent is pressure-dependent. Once again, confronted to not calculable modelisation errors, we consider as acceptable a range of $[0.45 ; 1.05]$ for $n$, but with a value for $\mathrm{e}_{2}$ of only $50 \%$. 
- $\mathbf{e}_{3}$ is derived from the relative gap between the sum of all the walls $\mathrm{Q}_{50}$ of a zone (calculated for each wall) and the envelope air leakage zone $\mathrm{Q}_{50}$ (measured directly), $\mathrm{E}_{3}$. This gap measures notably the modelisation error resulting from the hypothesis that the zero pressure between the guarded zone and adjacent zones is uniform, which is used in all successive subtractions. In the database of 456 measurements, this gap is less than $7 \%$ for $100 \%$.

A first database analysis allowed us to define each error estimation parameter (Table 3), $e_{i}$. For $e_{1}$ and $e_{3}$, after having fixed the upper $\left(\mathrm{e}_{1}=100 \%\right.$ if $\mathrm{E}_{1}=5 \%$ and $\mathrm{e}_{3}=100 \%$ if $\left.\mathrm{E}_{3}=3 \%\right)$ and lower $\left(\mathrm{e}_{1}=10 \%\right.$ if $\mathrm{E}_{1}=50 \%$ and $\mathrm{e}_{3}=80 \%$ if $\mathrm{E}_{3}=7 \%$ ) thresholds, we proposed to linearly extrapolate for intermediate values. For $\mathrm{e}_{2}$, only three threshold values are proposed.

Table 3. Proposed values to calculate a reliability index $I_{R}$

\begin{tabular}{ccc}
\hline $\mathbf{e}_{\mathbf{1}}(\mathbf{\%})$ & $\mathbf{e}_{\mathbf{2}}(\mathbf{\%})$ & $\mathbf{e}_{3}(\mathbf{\%})$ \\
\hline \hline $\mathrm{e}_{1}=100$, if $\mathrm{E}_{1}<5 \%$ & $\mathrm{e}_{2}=100$, if $\mathrm{n}[0.5 ; 1]$ & $\mathrm{e}_{3}=100$, if $\mathrm{E}_{3}<3 \%$ \\
$\mathrm{e}_{1}=\mathrm{c}^{*} \mathrm{E}_{1}+\mathrm{d}$, if $5 \% \leq \mathrm{E}_{1} \leq 50 \%$ & $\mathrm{e}_{3}=\mathrm{e}^{*} \mathrm{E}_{3}+\mathrm{f}$, if $3 \% \leq \mathrm{E}_{3} \leq 7 \%$ \\
$\mathrm{c}=-200$ and $\mathrm{d}=110$, obtained by linear \\
$\begin{array}{c}\text { extrapolation } \\
\mathrm{e}_{1}=0, \text { else }\end{array}$ & $\mathrm{e}_{2}=50$, if $\mathrm{n}[0.45 ; 1.05]$ & $\mathrm{e}=-500$ and $\mathrm{f}=115$, obtained by linear \\
extrapolation & $\mathrm{e}_{2}=0$, else
\end{tabular}

For the data available on 59 walls, in order to further investigate global errors including modelisation errors, we also calculated the relative gap between both $\mathrm{Q}_{50}$ of a single wall, the first one from the first guarded zone to the adjacent zone, the second one from this adjacent zone now considered as the guarded zone. In these 59 walls, 36 walls had $Q_{50}$ lower than $20 \mathrm{~m}^{3} \cdot \mathrm{h}^{-1}$; the 23 other walls had $\mathrm{Q}_{50}$ higher than $20 \mathrm{~m}^{3} \cdot \mathrm{h}^{-1}$. Analyzing data measured on the 36 walls with Q 50 lower than $20 \mathrm{~m}^{3} \cdot \mathrm{h}^{-1}$, we observed that only $16 \%$ (six partitions) had this gap lower than $20 \%$. When analyzing the other 23 walls with $\mathrm{Q}_{50}$ higher than $20 \mathrm{~m}^{3} \cdot \mathrm{h}^{-1}$, we observed as expected better results with $87 \%$ (20 partitions), which had this gap lower than $20 \%$. We did not include these interesting results in the reliablity index, because they were available for $9 \%$ of the walls of the database only.

Finally, if the number of relevant measurement points after the subtraction was less than 2 (because the others were negative), we considered $I_{R}=0 \%$. If one point was available, we assumed an exponent $n=2 / 3$ in order to calculate the air leakage coefficient $\mathrm{C}_{\mathrm{L}}$, according to eq. (5). If no point was available, the measurement was not included in the database. This did not occur when using device 2 and rarely before.

\section{RESULTS OF THE MEASUREMENT CAMPAIGN}




\section{Description of the database developed}

For each of the 456 internal partitions or exterior walls, the database developed includes general information on the building, the building's main characteristics, measurement data, and measurement results as shown in Table 4. This database was developed starting from the French envelope airleakage database (Bailly et al., 2015), but was adapted in order to get supplementary data necessary to analyse each internal partition or exterior walls. This supplementary data are in bold in the Table 4.

Table 4. Database description

\begin{tabular}{|c|c|c|c|}
\hline $\begin{array}{l}\text { General information on } \\
\text { building }\end{array}$ & $\begin{array}{l}\text { Building's main technical } \\
\text { characteristics }\end{array}$ & Measurement data & $\begin{array}{c}\text { Measurement results for } \\
\text { each internal partition or } \\
\text { exterior wall }\end{array}$ \\
\hline City & Certification & Wind exposition [-] & $\mathrm{C}_{\mathrm{L}}\left[\mathrm{m}^{3} \cdot \mathrm{h}^{-1} \cdot \mathrm{Pa}^{-\mathrm{n}}\right]$ \\
\hline Region & Main material & Outdoor temperature $\left[{ }^{\circ} \mathrm{C}\right]$ & n $[-]$ \\
\hline Building commissioning year & Structure type & $\begin{array}{l}\text { Wind velocity [Beaufort } \\
\text { scale] }\end{array}$ & $\mathrm{q}_{50}\left[\mathrm{~m}^{3} \cdot \mathrm{h}^{-1} \cdot \mathrm{m}^{-2}\right]$ \\
\hline \multirow[t]{7}{*}{ Number of levels } & Insulation type & Devices used & $\mathrm{ELA}_{4}\left[\mathrm{~cm}^{2}\right]$ eq.(4) \\
\hline & Ventilation system & Date & $\varepsilon_{1}[\%]$ \\
\hline & Heated volume $\left[\mathrm{m}^{3}\right]$ & Wall area $\left[\mathrm{m}^{2}\right]$ & $I_{R}[\%]$ \\
\hline & Floor area $\left[\mathrm{m}^{2}\right]$ & $\begin{array}{c}\text { Flow direction } \\
\text { (horizontal/vertical) }\end{array}$ & \\
\hline & Loss area $A_{\text {env }}\left[\mathrm{m}^{2}\right]$ & $\begin{array}{l}\text { Type of wall (internal } \\
\text { partition/exterior) }\end{array}$ & \\
\hline & $\begin{array}{l}\text { Envelope air leakage } \mathrm{q}_{\mathrm{a} 4} \text { (if } \\
\text { already available and } \\
\text { measured on-site) }\left[\mathrm{m}^{3} \cdot \mathrm{h}^{-1} \cdot \mathrm{m}^{-2}\right]\end{array}$ & $\begin{array}{c}\text { Type of room } \\
\text { (bedroom/bath/kitchen/ } \\
\text { toilet) }\end{array}$ & \\
\hline & $\begin{array}{l}\text { Type of intermediate floor } \\
\text { (wood, concrete, no) }\end{array}$ & & \\
\hline
\end{tabular}

\section{Measurement reliability analysis}

For all measurements, a reliability index, as proposed above, was calculated. Figure 3 (a) shows that measurement reliability was quite high: $73 \%$ of the data had a reliability index greater than $80 \%$. Moreover, $63 \%$ of the data had a $100 \%$ reliability index.

Figure 3 (b) shows that the lowest reliability indexes were for low air leakage rates. We also found high reliability indexes for low air leakage rates, and in some rare cases lower indexes for higher air leakage rates. This figure shows that the fixed threshold (Table 3) also had threshold impacts on the final calculated reliability index, with very few values within the ranges $[5-30 \%] ;[35-45 \%] ;[70-90 \%]$. 
Most of the measurements $(79 \%)$ were taken at wind velocities lower than 1 on the Beaufort scale (Figure 4a). Higher reliability indexes were found for lower wind velocities, but the median values were quite high even for high wind velocities (Figure 4b).
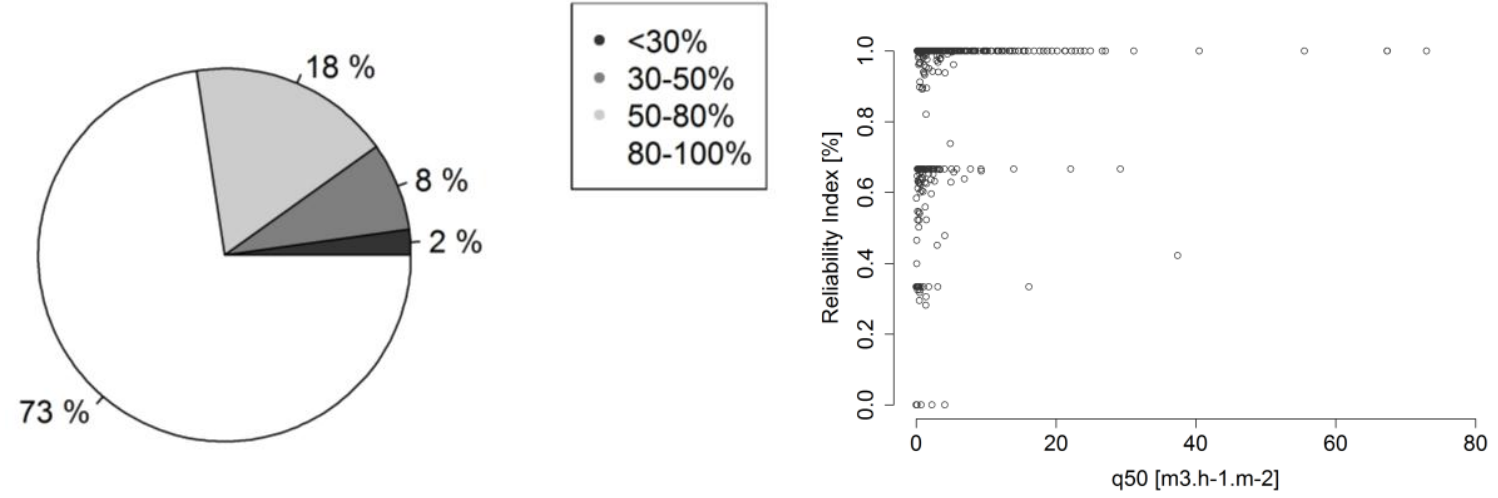

Figure 3 (a) Percentage of data in each reliability index class. (b) Reliability index as a function of the wall air leakage level.

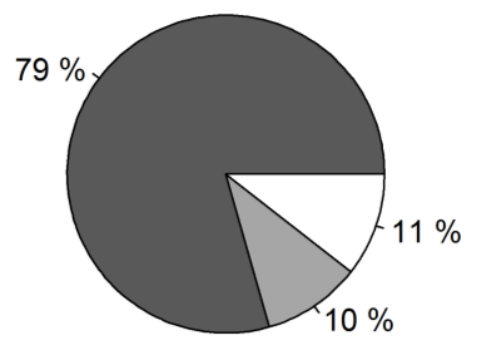

- $[0-1]$

- $[2-3]$ $[4-6]$

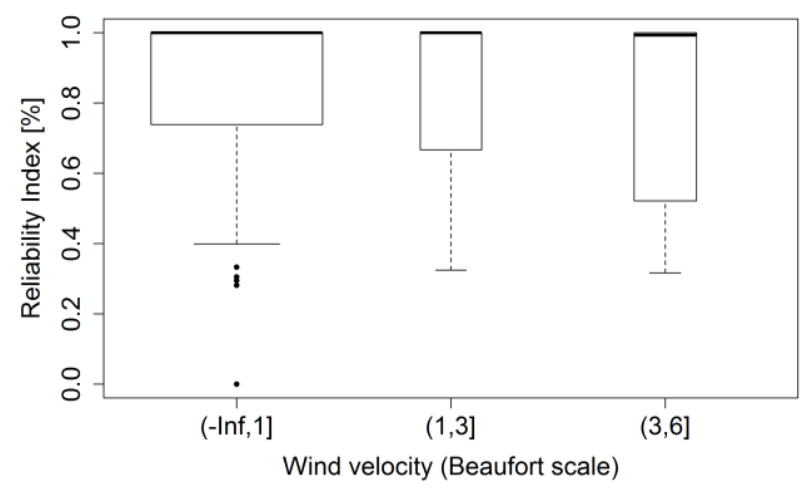

Figure 4 (a) Percentage of data in each wind velocity class (Beaufort scale). (b) Reliability index as a function of wind velocity.

\section{Analysis of key factors affecting internal partition and exterior wall air leakage}

Envelope airtightness level. Plotting wall air leakage as a function of envelope air leakage ( $\mathrm{q}_{\mathrm{a}}$, eq. (1)) for the 23 houses confirmed that exterior wall air leakage correlates well with envelope air leakage (Figure 5a), whereas internal partition wall air leakage was not at all related to envelope air leakage (Figure 5b). High air leakage on internal partitions 
can indeed be measured even if the envelope is quite airtight (houses 1, 2, 4, 5 on the graph).

Figure $5 \mathrm{a}$ also illustrates frequent dispersion of the values, even for airtight houses. Assuming a uniform distribution of the envelope air leakage on each exterior wall can also differ considerably from actual measurements.
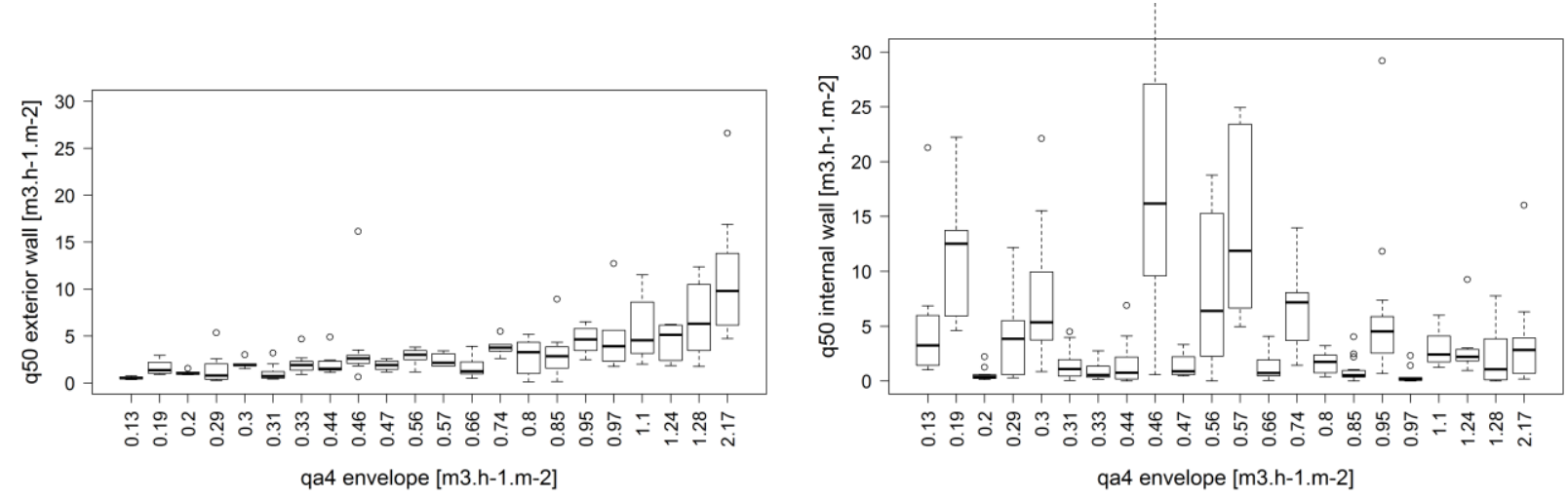

On the boxplots the black line shows the median value, the rectangle delimits the $1^{\text {st }}$ and the $3^{\text {rd }}$ quartile. White dots are extreme values higher/lower than 1.5 times the interquartile range, not included in the boxplot.

Figure 5 Influence of envelope air leakage on exterior wall (a) and internal partition wall (b) air leakage.

Ventilation systems. Ventilation systems could impact external air leakage due to the material - number of air outlets and inlets, size, type and accessories - and due to the quality of mounting. It could be assumed that with balanced systems more attention could be given to envelope airtightness because its quality is recognized as a condition for the efficiency of balanced ventilation.

Nevertheless, this impact is not shown by the data (Figure 6), even if the sample can be considered as quite small and any conclusions taken with caution.

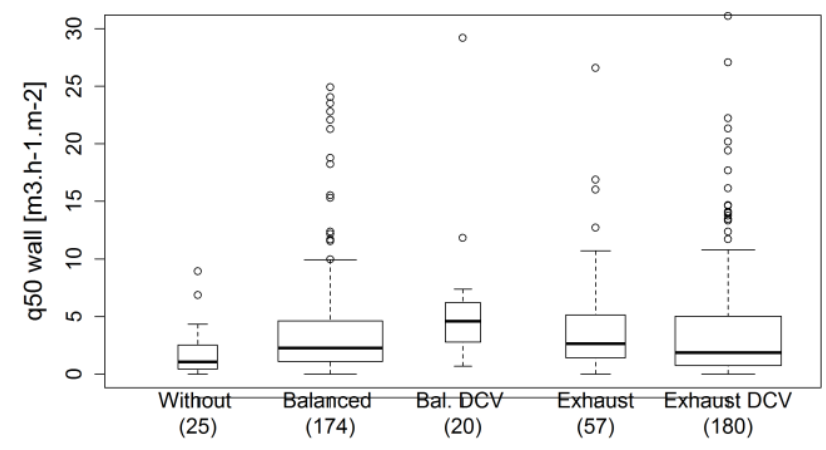


Figure 6 Impact of ventilation system on exterior wall air leakage (number of data).

Structure type: heavy vs. wood structure. We re-plotted internal partition wall air leakage as a function of envelope air leakage ( $\mathrm{q}_{\mathrm{a} 4}$, eq. (1)) for the 23 houses, distinguishing between heavy and wood structures (Figure 7); a strong correlation was observed. Wood-structure houses can have very airtight envelopes. However, because of a wood intermediate floor, for instance, or the lighter indoor partitions, we observed higher levels of internal air leakage than in heavy structures.

Figure 9 plots the ratio of interior partition air leakage and envelope air leakage for the two types of structure. Firstly, the median value of this ratio was nine times lower in heavy structures (1.9) than in wood structures (17.6). Moreover, there was greater dispersion of the values for wood structures, with 4.0 the interquartile range (IQR) of the ratio, than for heavy structures, with 38.3 the interquartile range (IQR) of the ratio.

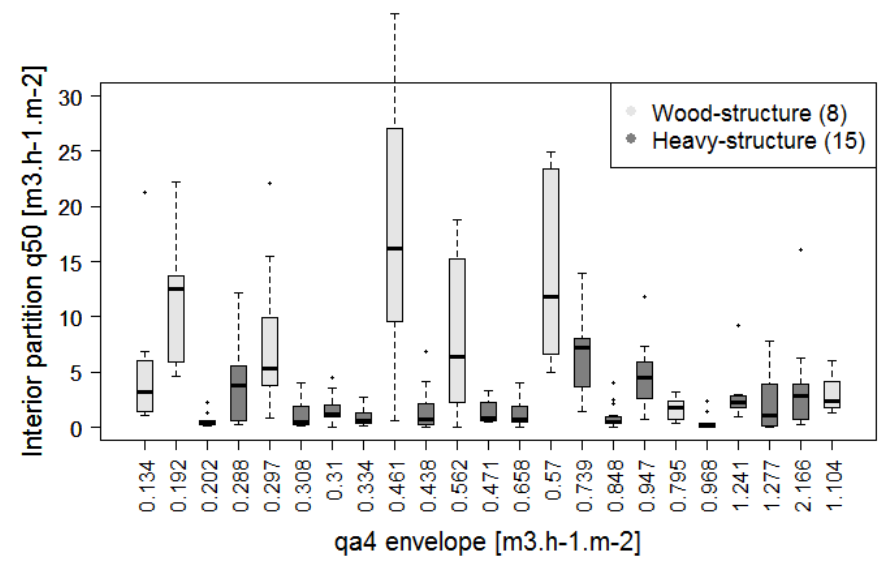


Figure 7 Interior partition air leakage as a function of envelope air leakage, depending of the type of structure.

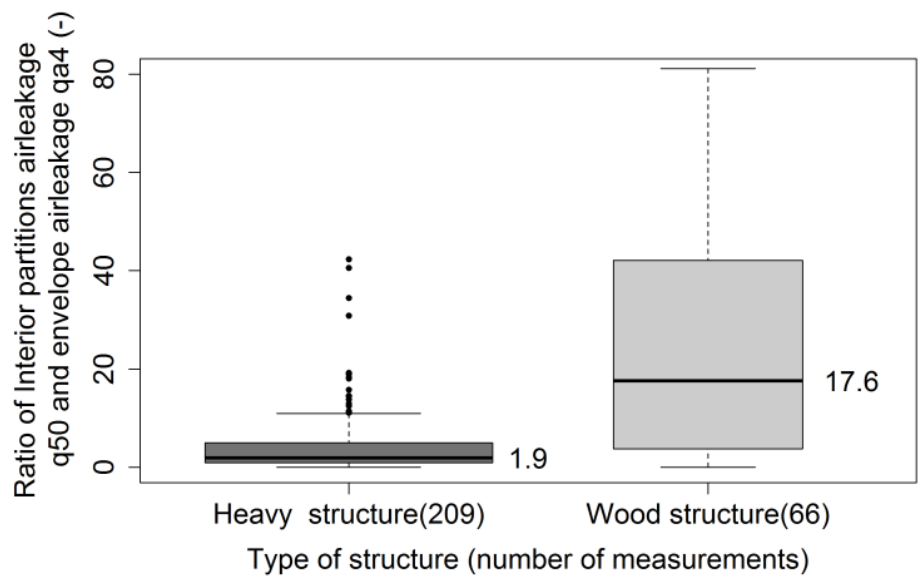

Figure 8 Impact of the type of structure on the ratio of internal partition walls air leakage and envelope air leakage.

Room type: bedroom vs bathroom. The fact that bathrooms are often built with more airtight surface materials (tiled floors, tiled walls) than bedrooms (parquet floors, no tiling) may have an impact on internal partition and exterior wall air leakage. To study this impact, we plotted in Figure 9 wall air leakage depending on the type of structure and the type of room. In this figure, the air leakage of a wall separating a bathroom from a bedroom is plotted twice (in each category). The figure shows that the type of room has no influence and confirms that the type of structure has greater influence.

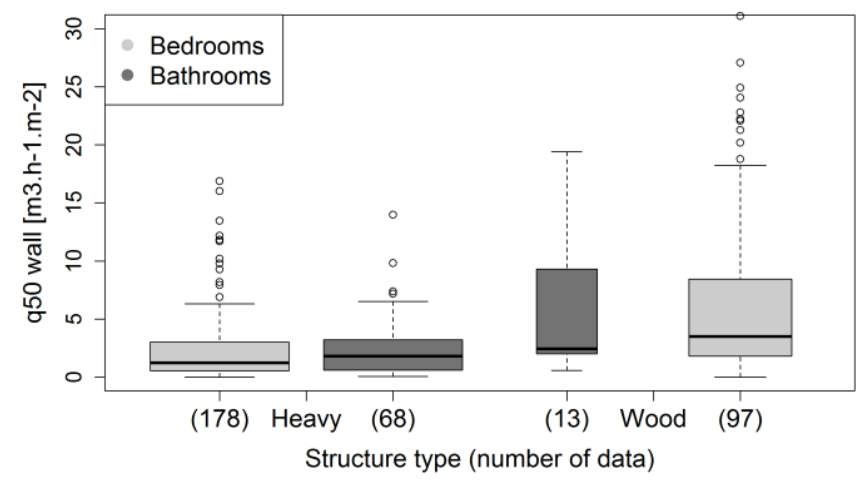


Figure 9 Influence of the type of room on exterior wall air leakage.

Wall type: exterior vs. internal partition. Figure 10 represents air leakage depending on the type of structure and the location of the wall: exterior wall (ext), internal partition wall (int), exterior and internal partition (ext\&int). This category corresponds to measurements taken only on room envelopes, in the toilet for instance. Analysis of these data is less relevant because of the size of the sample (only 13 for wood and 19 for heavy structure data). Once again, considerable differences were found depending on the type of structure. Firstly concerning the median values, the exterior and internal partition wall air leakage differed by a factor of 2 for heavy structures $\left(\mathrm{q}_{50}=2.3 \mathrm{~m}^{3} \cdot \mathrm{h}^{-1} \cdot \mathrm{m}^{-2}\right.$ for exterior vs. $\mathrm{q}_{50}=1.2 \mathrm{~m}^{3} \cdot \mathrm{h}^{-1} \cdot \mathrm{m}^{-2}$ for internal partition walls $)$ and a factor of 0.5 for wood structures $\left(\mathrm{q}_{50}=2.4 \mathrm{~m}^{3} \cdot \mathrm{h}^{-1} \cdot \mathrm{m}^{-2}\right.$ for exterior vs. $\mathrm{q}_{50}=6.0 \mathrm{~m}^{3} \cdot \mathrm{h}^{-1} \cdot \mathrm{m}^{-2}$ for internal partition walls). For heavy structures, internal partition walls were more airtight than exterior walls, whereas we observed the contrary for wood structures. Secondly, concerning the differences in the dispersion of the values, the values for internal partition and exterior walls were similar for heavy structures, with an IQR of $3.5 \mathrm{~m}^{3} \cdot \mathrm{h}^{-1} \cdot \mathrm{m}^{-2}$ for exterior walls vs. $2.7 \mathrm{~m}^{3} \cdot \mathrm{h}^{-1} \cdot \mathrm{m}^{-2}$ for internal partition walls. For wood structures, the difference in dispersion was stronger with an IQR of $1.8 \mathrm{~m}^{3} \cdot \mathrm{h}^{-1} \cdot \mathrm{m}^{-2}$ for exterior walls vs. $12.3 \mathrm{~m}^{3} \cdot \mathrm{h}^{-1} \cdot \mathrm{m}^{-2}$ for internal partition walls.

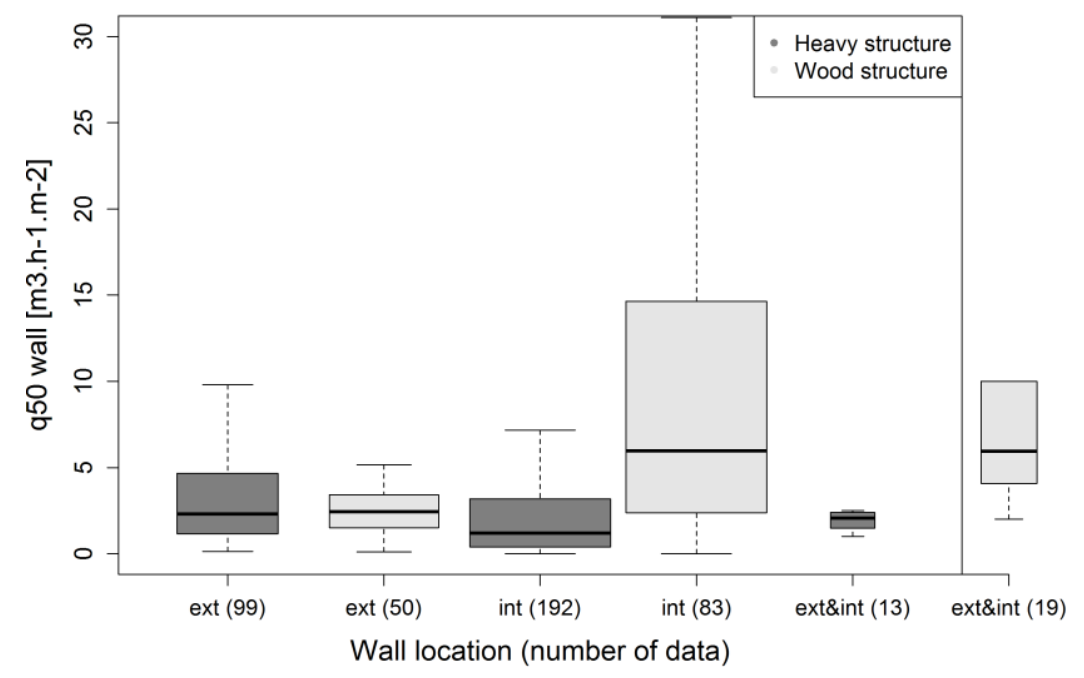


Figure 10 Influence of wall location on wall air leakage.

\section{Internal air leakage significant compared to door undercuts}

In dwellings, mechanical ventilation is often based on fresh air inlets in bedrooms and the living room and exhaust air outlets in humid rooms (kitchen, bathroom, toilet). When doors are closed, we commonly assume that the dwelling is aired from door undercuts. These new data on internal partition wall air leakage allowed us to compare the size of door undercuts with the size of air leakage paths located on internal partition walls. We used eq. (4) to calculate the equivalent air leakage area $\mathrm{ELA}_{4}\left[\mathrm{~cm}^{2}\right]$ for each internal partition wall. We plotted this indicator depending on the type of structure and the number of levels (Figure 11) in the house. We considered the calculated median values and multiplied this by 3 for one-level homes, assuming that we had at least three interior walls, and by 4 for two-level houses. As a result, internal partition wall air leakage accounted for $9 \mathrm{~cm}^{2}$ (one-level structure), $24 \mathrm{~cm}^{2}$ (two-level heavy structure) or $120 \mathrm{~cm}^{2}$ (two-level wood structure). A door undercut is around $90 \mathrm{~cm}^{2}$, so that internal partition wall air leakage was fairly considerable.

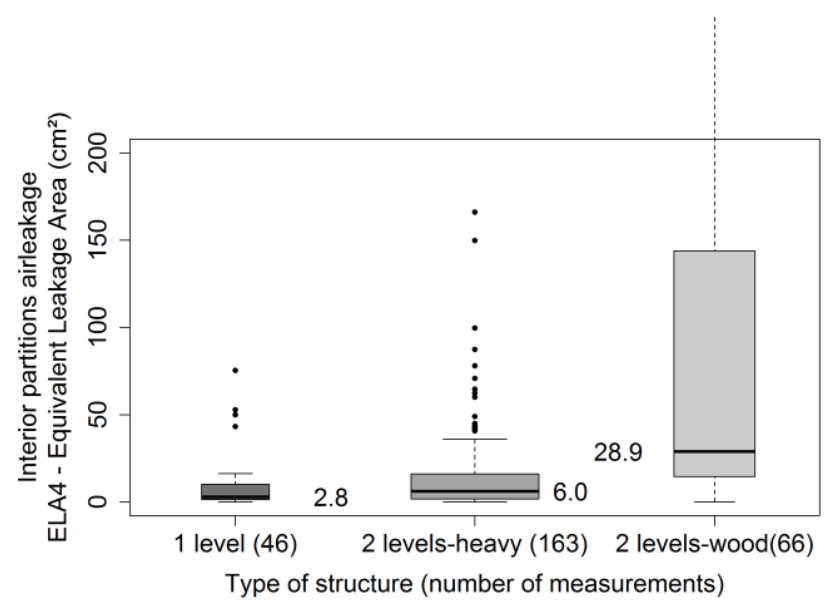

Figure 11 Internal partition wall equivalent air leakage area $\left(\mathrm{cm}^{2}\right)$ depending on the type of structure.

\section{A proposal for air leakage values and dispersion input data for multizone IAQ models}

Internal partition wall air leakage should be considered as well as door undercuts considering their substantial impacts on dwelling airing. With this study and these new data, we suggest input values for multizone airflow modelling to predict airflows and IAQ more precisely. According to Figure 8 and Figure 10, we suggest (Table 5) using the median values as reference values and considering a distribution of these values, according to the IQR calculated. 
Concerning exterior wall air leakage data, databases exist in France (85 000 dwellings, Bailly et al., 2015) and in other countries (100 000 dwellings in the USA: Walker et al., 2013). The present study has produced new information on the dispersion of envelope air leakage. In models used in EP regulation calculation methods, we often assume that envelope air leakage is uniformly distributed in each of the dwelling's exterior walls, for instance, prorating the total air leakage according to the ratio between wall area and envelope area (CEN, 2007), (JO, 2011). This study has shown that an IQR can represent $150 \%$ of the median value for heavy structures and $75 \%$ for wood structures. We would also recommend using these IQR ratios applied to the envelope air leakage value, once converted in $\mathrm{q}_{50}$.

Finally, we would recommend using these values only for single family dwellings, and for "heavy structures" defined as concrete, brick or concrete blocks structures with concrete intermediate floor, and "wood structures" defined as wood post-and-beam framing with a wood intermediate floor.

Table 5. Proposal of air leakage input data for multizone IAQ models single family dwellings

\begin{tabular}{|c|c|c|}
\hline $\begin{array}{l}\text { Internal partition wall air leakage } \\
\text { reference value }\end{array}$ & $\begin{array}{c}\text { Internal partition wall air leakage } \\
\text { distribution }\end{array}$ & Exterior wall air leakage distribution \\
\hline $\begin{array}{c}\text { Heavy structure: } \mathrm{q}_{50}=1.2 \mathrm{~m}^{3} \cdot \mathrm{h}^{-1} \cdot \mathrm{m}^{-2} \\
\text { or } \mathrm{q}_{50} / \mathrm{q}_{\mathrm{a} 4}=2\end{array}$ & $\begin{array}{c}\text { Heavy structure: IQR }\left(\mathrm{q}_{50}\right)=3 \mathrm{~m}^{3} \cdot \mathrm{h}^{-1} \cdot \mathrm{m}^{-2} \\
\text { or IQR }\left(\mathrm{q}_{50} / \mathrm{q}_{\mathrm{a} 4}\right)=4\end{array}$ & $\begin{array}{l}\text { Heavy structure: } \mathrm{IQR}=150 \% \text { of the } \\
\text { envelope air leakage value in } \mathrm{q}_{50}\end{array}$ \\
\hline $\begin{array}{c}\text { Wood structure: } \mathrm{q}_{50}=6 \mathrm{~m}^{3} \cdot \mathrm{h}^{-1} \cdot \mathrm{m}^{-2} \\
\text { or } \mathrm{q}_{50} / \mathrm{q}_{\mathrm{a} 4}=17.5\end{array}$ & $\begin{array}{c}\text { Wood structure: } \mathrm{IQR}\left(\mathrm{q}_{50}\right)=12 \mathrm{~m}^{3} \cdot \mathrm{h}^{-1} \cdot \mathrm{m}^{-2} \\
\text { or IQR }\left(\mathrm{q}_{50} / \mathrm{q}_{\mathrm{a} 4}\right)=38.5\end{array}$ & $\begin{array}{l}\text { Wood structure: } \mathrm{IQR}=75 \% \text { of the } \\
\text { envelope air leakage value in } \mathrm{q}_{50}\end{array}$ \\
\hline
\end{tabular}

\section{CONCLUSION AND OUTLOOK}

The present paper develops a performance-based approach for ventilation in low-energy dwellings, integrating indoor air quality and health issues. The paper provides new data that could be useful for detailed modelling of internal and external air leakage, with consequences on IAQ bedrooms where people spend most of their time. This paper presents an innovative detailed database including air leakage of 456 exterior and internal partition walls measured in 23 detached houses. Each wall air leakage is described with a reliability index that we have developed, in order to describe the confidence in the airleakage measurement. This paper analyses this new database, pointing out that building structure is the most influent parameter on interior partition air leakage. This analysis also highlights that actual measurements contradict the assumption that air leakage is uniformly distributed, as often claimed in EP calculations and in IAQ 
multizone models used in regulations. As a conclusion of this analysis, the paper recommends values to take into account internal partition wall air leakage and to consider non-uniform distributions for air leakage in dwelling multizone IAQ models.

On-going developments concern the numerical part of this study. With these new data, we will further analyse the influence of non-uniform internal and external air leakage on airflows in single-family dwellings, with more building geometries, other ventilation systems and higher levels of internal partition air leakage. The multizone airflow model will be completed with an IAQ model, based on emissions and occupant scenarios. The final aim of this model is to evaluate the IAQ performance at the design stage of every new low energy single-family dwelling.

\section{ACKNOWLEDGMENTS}

Cerema is funded by the French Ministry of the Environment, See and Energy (MEEM) and the Ministry for Sustainable Housing and Habitat (MLHD). The sole responsibility for the content of this publication lies with the authors.

\section{NOMENCLATURE}

ACR: $\quad$ Air change rate per hour $\left[\mathrm{h}^{-1}\right]$

$A_{\text {env: }} \quad$ Building envelope area excluding the lowest floor $\left[\mathrm{m}^{2}\right]$

Bal.DCV: Humidity-controlled balanced ventilation

BBC: $\quad$ The 2005 French low-energy certification, a first step before the RT 2012

$\mathrm{C}_{\mathrm{L}}$ : $\quad$ The air leakage coefficient $\left[\mathrm{m}^{3} \cdot \mathrm{h}^{-1} \cdot \mathrm{Pa}^{-\mathrm{n}}\right]$

DCV Ex: Exhaust ventilation

EP: Energy-performance

IAQ: Indoor air quality

IQR: Interquartile range [-]

$\mathrm{I}_{\mathrm{R}}: \quad$ Reliability index [\%]

n: $\quad$ Airflow exponent [-]

$\mathrm{N}$ : $\quad$ Number of points of measure in a depressurization test [-]

$\mathrm{n}_{50}$ : Air leakage rate at $50 \mathrm{~Pa}\left[\mathrm{~h}^{-1}\right]$

$\Delta \mathrm{p}:$ Pressure difference $[\mathrm{Pa}]$

Q: $\quad$ Airflow due to airleakage $\left[\mathrm{m}^{3} \cdot \mathrm{h}^{-1}\right]$

Q50: Airleakage rate at $50 \mathrm{~Pa}\left[\mathrm{~m}^{3} \cdot \mathrm{h}^{-1}\right]$

$\mathrm{q}_{\mathrm{a}}$ : Building envelope air leakage rate at $4 \mathrm{~Pa}$, normalized by the envelope area $\mathrm{A}_{\mathrm{env}}\left[\mathrm{m}^{3} \cdot \mathrm{h}^{-1} \cdot \mathrm{m}^{-2}\right]$

q50: Air leakage rate at $50 \mathrm{~Pa}$, normalized by the surface area of the measured wall $\left[\mathrm{m}^{3} \cdot \mathrm{h}^{-1} \cdot \mathrm{m}^{-2}\right]$

RT 2012: The most recent French building energy-performance regulation

\section{REFERENCES}


AFNOR, 2014. GA P50-784 Décembre 2014, Performance thermique des bâtiments - Guide d'application de la norme NF EN 13829:2001

Alfano, F.R. d'Ambrosio, Dell'Isola, M., Ficco, G., Tassini, F., 2012. Experimental analysis of air tightness in Mediterranean buildings using the fan pressurization method. Building and Environment 53, 16-25. doi:10.1016/j.buildenv.2011.12.017

ASHRAE, 2001. International Weather for Energy Calculation (IWEC) Weather files, C 2001 American Society of Heating, Refrigerating and Air-Conditioning Engineers (ASHRAE), Inc., Atlanta, GA, USA. www.ashrae.org,

ASTM, 2010. ASTM E779 - 10. Standard Test Method for Determining Air Leakage Rate by Fan Pressurization

Bailly, A., Guyot, G., Leprince, V., 2015. 6 years of envelope airtightness measurements performed by French certified operators: analyses of about 65.000 tests, in: 36th AIVC Conference "Effective Ventilation in High Performance Buildings." Madrid, Spain,.

Boulanger, X., Mouradian, L., Pele, C., Pamart, P.Y., Bernard, A.-M., 2012. Lessons learned on ventilation systems from the LAQ calculations on tight energy performant buildings, in: AIVC-Tightvent Conference Proceedings. Copenhagen, pp. 40-43.

Bracke, W., Laverge, J., Bossche, N.V.D., Janssens, A., 2016. Durability and Measurement Uncertainty of Airtightness in Extremely Airtight Dwellings. International Journal of Ventilation 14, 383-394. doi:10.1080/14733315.2016.11684095

Carrié, F.., Leprince, V., 2014. Model error due to steady wind in building pressurization tests, in: 35th AIVC Conference "Ventilation and Airtightness in Transforming the Building Stock to High Performance." Poznań, Poland.

CEN, 2007. BS EN 15242:2007 - Ventilation for buildings. Calculation methods for the determination of air flow rates in buildings including infiltration.

Delmotte, C., Laverge, J., 2011. Interlaboratory Tests for the Determination of Repeatability and Reproducibility of Buildings Airtightness Measurements, in: AIVC Conference Proceedings. Brussels, Belgium.

Delmotte, C., 2013. Airtightness of buildings - Calculation of combined standard uncertainty, in: AIVC Conference. Athens, Greece.

Du, L., Batterman, S., Godwin, C., Chin, J.-Y., Parker, E., Breen, M., Brakefield, W., Robins, T., Lewis, T., 2012. Air Change Rates and Interzonal Flows in Residences, and the Need for Multi-Zone Models for Exposure and Health Analyses. Int. J. Environ. Res. Public Health 1639-4661.

Emmerich, S.J., Gorfain, J.E., Howard-Reed, C., 2003. Air and Pollutant Transport from Attached Garages to Residential Living Spaces - Literature Review and Field Tests. International Journal of Ventilation 2, 265-276. doi:10.1080/14733315.2003.11683670

EN ISO 9972, 2015. "Determination of air permeability of buildings - Fan pressurization method"

Erhorn, H., Erhorn - Kluttig, H., Carrié, F.., 2008. Airtightness requirements for high performance buildings, in: 29th AIVC Conference. Presented at the Advanced building ventilation and environmental technology for addressing climate change issues, Kyoto, Japan.

Fürbringer, J.., Roecker, C., Roulet, C.-A., 1988. The use of a guarded zone pressurization technique to measure air flow permeabilities of a multizone building, in: 9th AIVC Conference. Gent, Belgium, pp. 13-30.

Gustavsen, S., Bekö, G., Toftum, J., Clausen, G., 2012. Interyonal airflows in five Danish homes during two seasons, in: Healthy Building 2012. Brisbane.

Herrlin, M.K., Modera, M.P., 1988. Analysis of errors for a fan-pressurization technique for measuring inter-zonal airleakage, in: 9th AIVC Conference. Gent, Belgium, pp. 12-30.

Hult, E.., Dickerhoff, D., Price, P., 2012. Measurement methods to determine air leakage between adjacent zones (No. LBNL- 5887E). LBNL.

Hult, E.., Sherman, M.H., 2014. Estimates of Uncertainty in Multi-Zone Air Leakage Measurements. The International Journal of Ventilation, Vol. $12 \mathrm{~N}^{\circ} 4$.

ISO/IEC, 2008. ISO/IEC Guide 98-3:2008 - Uncertainty of measurement -- Part 3: Guide to the expression of uncertainty in measurement (GUM:1995).

JO, 1982. Arrêté du 24 mars 1982 consolidée relatif à l'aération des logements : aération générale ou permanente. JO du 15 novembre 1983. JO, 2011. Méthode de calcul Th-BCE 2012. Annexe à l'arrêté portant approbation de la métbode de calcul Th-BCE 2012.1377 p.

Kim AK and Shaw CY: (1986). Seasonal variation in airtightness of two detached houses., Measured Air Leakage of Buildings. National Research Council Canada (NRC).

Jokisalo, J., Kalamees, T., Kurnitski, J., Eskola, L., Jokiranta, K., Vinha, J., 2008. A Comparison of Measured and Simulated Air Pressure Conditions of a Detached House in a Cold Climate. Journal of Building Physics 32, 67-89. doi:10.1177/1744259108091901

Laverge, J., Pattyn, X., Janssens, A., 2013. Performance assessment of residential mechanical exhaust ventilation systems dimensioned in accordance with Belgian, British, Dutch, French and ASHRAE standards. Building and Environment 59, 177-186. doi:10.1016/j.buildenv.2012.08.018

Laverge, J., Janssens, A., 2013. Optimization of design flow rates and component sizing for residential ventilation. Building and Environment 65, 81-89. doi:10.1016/j.buildenv.2013.03.019 
Murphy W et al.: (1991). A round robin test of Fan Pressurization Devices. ASHRAE Vol. RP-594.

Offerman, F.J., 2009. Ventilation and Indoor Air Quality in New Homes, PIER Energy-related environmental research Program. Collaborative Report. CEC-500-2009-085. California Air resources Board and Energy Commission.

Persily A: (1982). Repeatability and Accuracy of Pressurization Testing, ASHRAE/DOE Conference on Thermal Performance of the Exterior Envelope of Buildings.

Reardon, J.T., Kim, A.K., Shaw, C.Y., 1987. Balanced fan depressurization method for measuring component and overall air leakage in single and multi family dwellings. ASHRAE Transactions 93, $15 \mathrm{p}$.

Richieri, F., Moujalled, B., Samri, D., Bourdassol, M., Carrié, F.-R., 2013. Numerical evaluation of the airtightness impact on energy needs in mechanically ventilated dwellings, in: 8th International BUILDAIR-Symposium. Hannover, Germany, p. 11 p.

Roldan, A., Allard, F., Achard, G., 1987. Influence of infiltrations and inter-room air flows on thermal loads in multizone buildings. in: Third International Congress on Building Energy Management, ICBEM 87. Presented in Lausanne, pp. 178-185.

Shaw, C.Y., 1980. Methods for conducting small-scale pressurization tests and air leakage data of multi-story apartment buildings. ASHRAE Transactions 86 (1), pp. 214-250.

Sherman, M., 1992. A Power-Law Formulation of Laminar Flow in Short Pipes. Journal of Fluids Engineering, (LBL report 29414, Lawrence Berkeley Laboratory, University of California). 114, pp. 601-605.

Sherman, M.H., Palmiter, L., 1995. Uncertainties in fan pressurization measurements, in: ASTM: Airflow Performance Conference.

Walker, I.S., Wilson, D.J., Sherman, M.H., 1998. A comparison of the power law to quadratic formulations for air infiltration calculations. Energy and Buildings 27, 293-299. doi:10.1016/S0378-7788(97)00047-9

Walker, I.S., Sherman, M.H., Joh, J., Chan, W.R., 2013. Applying Large Datasets to Developing a Better Understanding of Air Leakage Measurement in Homes. The International Journal of Ventilation, VEETECH Ltd.

Walton, G.N., Emmerich, S.J., 1994. CONTAM93: a multizone airflow and contaminant dispersal model with a graphic user interface. Air Infiltration Review 16, 6-8. 